\title{
COVID-19 in 2021: A Call for Collaboration
}

\author{
Duncan Selbie
}

For many years now the world has anticipated a global pandemic. Aware of the devastating impact of pandemic influenza after the first World War, we have been awaiting a similar threat and the changes it would bring to our way of life, health, and the global economy.

Alarm bells rang out loud and clear with significant epidemics in recent years. Outbreaks of severe acute respiratory syndrome (SARS), Ebola, and Zika provided an indication of the health, social, economic, and political impacts that rapid infectious disease spread can have in a globally interconnected world. This did accelerate preparations, but as we have seen, significant weaknesses in global systems have been exposed.

The world has been on a journey to build preparedness and epidemic and pandemic response capacity. The International Health Regulations, which were updated in 2005, provided a clear framework against which countries could assess their capacity to respond, with an 'all hazards' response to potential threats.

However, the World Health Organization's (WHO) Joint External Evaluation (JEE) process helped highlight that significant weaknesses remained after more than 100 countries undertook voluntary assessments of their global health security status (1). Efforts to mobilize global resources to strengthen preparedness were underway, and progress was being made, but it is now clear, with the benefit of hindsight, that in many cases preparations were too little, too narrow, and too late.

As I look ahead at the coming year, I am very aware that the challenges of coronavirus disease 2019 (COVID-19) remain high the world over. Whilst there is light at the end of a long and dark tunnel in the form of vaccines and with some good examples of the success of non-pharmaceutical interventions in some countries, it is clear that without successful, global distribution of effective vaccines, the shutting down of international borders and limitations of our social and economic lives will have increasing long term and devastating impacts on our health and wellbeing.

There have however been huge positive developments and innovations, and it is important to recognize and celebrate these. There has been unprecedented international scientific collaboration in support of developing diagnostic tests for COVID-19, in vaccine development and in finding life-saving treatments for patients with COVID-19, such as dexamethasone. We have seen hugely valuable international collaboration and sharing of information and experiences between countries, which have provided a deeper understanding of the nature of the virus and its mutations, and I am immensely proud of the work that the International Association of National Public Health Institutes (IANPHI) has done to facilitate exchanges between National Public Health Institutes from high income and low and middle income countries (2). This global collaboration and meeting of minds is something that we must build upon - strengthening the partnerships that have been established to ensure that we not only build back our national systems better, but we also build improved international collaboration.

IANPHI is a partnership between National Public Health Institutes, with China CDC being an active and important member. Sharing of information between countries including on China's national approach has helped to inform IANPHI members and regular exchanges have reinforced the value of peer-topeer support, which is the glue that binds us together across 100 member countries.

IANPHI now has a vital role to play working alongside partners like the WHO. Over the coming year, one of my greatest priorities as President of IANPHI will be to strengthen that relationship and ensure the collective capability of the world's National Public Health Institutes come together with a common purpose.

In looking forward, I believe we have important choices to make as a global community. We could all prioritize our national interests and turn inwards to protect our own people and economies, or we can recognize that until the world is safe, the global community never can be. It is clear and obvious that we need to reach out, work together, and build on the collaboration that COVID-19 has prompted.

There are some important mechanisms for international collaboration that have been developed and the key one I want to mention is COVAX, which is a global mechanism launched by the Coalition for 
Epidemic Preparedness (CEPI), Gavi (the Vaccine Alliance) and the WHO, to ensure that all countries have equitable access to effective COVID-19 vaccines (3).

Whilst it is understandable that every country will want to prioritize protecting their own most vulnerable people, over the medium to longer term, it is clear that we will never be safe until COVID-19 is controlled in every country. We have already seen the emergence of some more transmissible mutations of COVID-19 (4-6), and mutations will continue to develop wherever disease transmission continues unchecked. Therefore, we must work together, through a fair and equitable system, to support access to vaccines.

Those countries that have the money to support countries with less resources should look to mechanisms such as COVAX and seek to pool their financing for the global good. We must resist the temptation to use access to vaccines as a tool for global diplomacy and a vehicle for competition between countries - it is far more important that we work together in solidarity. This is true also for global data sharing, research, and development and for equitable access to diagnostics, treatments, medical goods, and personal protective equipment (PPE). This is something that IANPHI will champion and that I am personally committed to. We must also work together as a global public health community to counter the misinformation that surrounds vaccine hesitancy that damages the public's trust in vaccination.

To ensure we are better prepared for future pandemics we need to fully understand COVID-19 and openly share our findings on the management and science of the virus. We also need to maintain a One Health approach to global public health, which recognizes that human health is connected to the health of animals and the environment and that multiple sectors need to work together to achieve better public health outcomes. This is important not only to counter the threat of zoonotic disease but also to address the wider determinants of health. The link between COVID-19, obesity, and chronic diseases such as hypertension and diabetes highlights the need for global health security to also be linked to broader health system strengthening. The non-pharmaceutical interventions, including lockdowns, which public health systems have employed is another important area for sharing experience and learning, and for developing an evidence base on what has been effective.

Although the year ahead holds many challenges, I believe that we are stronger together, and believe we can build global capability for inclusive, resilient health systems, and champion Universal Health Coverage under UN Sustainable Development Goal 3 (7). I am looking forward to using the platform that IANPHI has developed to strengthen global partnerships and to strengthen public health systems globally.

doi: $10.46234 / \mathrm{ccdcw} 2021.034$

\# Corresponding author: Duncan Selbie, duncan.selbie@gmail.com.

Submitted: January 19, 2021; Accepted: January 29, 2021

\section{REFERENCES}

1. World Health Organization. Joint external evaluation (JEE) mission reports. https://www.who.int/ihr/procedures/mission-reports/en/. [20211-17]

2. The International Association of National Public Health Institutes. COVID-19 resources for members and global public health professionals. http://www.ianphi.org/news/2020/covid-resources.html. [2021-1-17].

3. The Vaccine Alliance. COVAX - the vaccines pillar of the access to COVID-19 tools (ACT) accelerator. https://www.gavi.org/covax-facility. [2021-1-17].

4. Wang L, Bi YF, Gao GF. Epidemiological model suggests D614G spike protein mutation accelerates transmission of COVID-19 - worldwide, 2020. China CDC Wkly 2020;2(49):946-7. http://dx.doi.org/10. $46234 / \mathrm{ccdcw} 2020.247$.

5. Chen HY, Huang XY, Zhao X, Song Y, Hao P, Jiang H, et al. The first case of new variant COVID-19 originating in the United Kingdom detected in a returning student - Shanghai Municipality, China, December 14, 2020. China CDC Wkly 2021;3(1):1-3. http://dx.doi.org/10.46234/ccdcw2020.246.

6. Chen FJ, Li BS, Hao P, Song Y, Xu WB, Liu NK, et al. A case of new variant COVID-19 first emerging in South Africa detected in airplane pilot - Guangdong Province, China, January 6, 2021. China CDC Wkly 2021;3(2):28 - 9. http://dx.doi.org/10.46234/ccdcw2021.007.

7. United Nations. UN sustainable development goal 3. https://sdgs. un.org/goals/goal3. [2021-1-17]

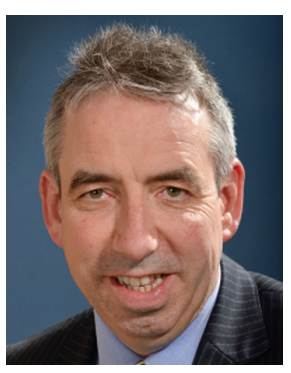

Professor Duncan Selbie

President, International Association of National Public Health Institutes

Former Chief Executive, Public Health England 